\title{
nature
}

\section{British physicians cool on civil defence}

\section{The British Medical Association argues that its government's recipe for defence against nuclear attack is ineffectual. But we all knew that. The question remains of what to do.}

AgAINST the odds, the British Medical Association is rapidly emerging as one of the most persistent of the British Government's critics. The association has already protested at two pieces of legislation now in the parliamentary mill - the totally inadequate bill to regulate the use of data banks, which would give the authorities access to computerized personal medical records in the pursuit of crime without the consent of physicians or their patients (see Nature 296, 694; 1982), and the provisions of the Police and Criminal Evidence Bill that would require police physicians to carry out "body searches" (a euphemism for anal and vaginal examinations) as instructed and also empower judges to order the production of medical records in vaguely defined circumstances. Now, the association's Board of Science and Education has produced a cool report of its Inquiry into the Effects of Nuclear War, the effect of which will be to cast doubt on the British Government's pronouncements on civil defence. The government department principally concerned is again the Home Office, the luckless (in the sense of consistently unlucky) sponsor of all three measures.

Neither the Home Office nor the British Medical Association has picked this quarrel. The Home Office is merely following the instructions implied in the present government's legitimate decision that civil defence against nuclear attack should not indefinitely be left on one side, and has dutifully been issuing advice to individuals about the best way of securing a measure of protection against heat or fallout (blast is commonly and rightly supposed to be an unavoidable fact of nuclear war), arranging for the continuation of government by other means (devolution to regional commissioners) and giving physicians advice as to how best to prepare for serious trouble. The association, well constructed for representing to government the special interests of physicians but constitutionally the creature of its physician members, has been impelled along the road to conflict by a decision of a representative conference two years ago. The outcome of the study by a committee set up for just this purpose is all the more persuasive because it has been, as they say in trade union circles, mandated. Procedurally, the association has had the wit (and also the clout) to take formal evidence from civil servants, and to write down what its witnesses have said. Politically, it is known not to have an axe to grind, at least on this issue. Practically, the association's report is uncontentious in that it merely confirms what has been known all along - that a serious attack with nuclear weapons would be the end of the United Kingdom.

The fine print in the report is instructive and even, in its macabre way, amusing. The association's working party, in need of some estimate of how many megatons of nuclear weapons might be exploded over Britain in the case of a nuclear attack, considers that the Home Office may have underestimated in supposing a mere $\mathbf{2 0 0}$ megatons, three per cent of the warhead capacity of the Warsaw Pact, would be let off, and entertains the possibility that three times as much damage might be done. It goes on to point out the difficulties that will be faced by individuals wondering how best to protect themselves against being killed: a shelter in the middle of a house or building will be vulnerable to the destruction of the whole by blast, one near the outside will expose the occupants to more radiation from fallout radiation. There is a long catalogue of the particular medical supplies whose general availability will be in jeopardy after a nuclear attack and a possibly constructive criticism of the Home Office's planning for a war that has not yet come in its neglect of the need for blood transfusions, if necessary by amateurs. The report notes in passing that the problem of burying the dead may not be proportionately as serious a problem as for the US Army that occupied the Philippines in 1944 because many potential corpses will have been vaporized. The load of psychiatric disorder among the survivors will nevertheless be horrendous and will go untreated. Everybody knows, of course, to whom the survivors' envy will be directed.

What, then, is to be made of the British Medical Association's report on nuclear war? One thing is clear - it has no place in that genre which seeks to frighten people into some other way of thinking or even voting. It is rather a pedestrian document, more concerned with detail than with principle. There is not even, as there might have been, a set of recommendations as to how physicians should behave in the aftermath of a nuclear attack. Should they do nothing until the intensity of ground-borne radiation has declined, hazard themselves so as to save the viable among the survivors or do the Hippocratic thing and treat the first survivor they come across? Rather by its neglect of this professional and philosophical question than by its recommendations as to how physicians should behave in an "emergency", the committee responsible declares its hand: the post-attack future cannot be foreseen by the simple extrapolation of the present.

In this poignant argument, the Home Office also has a case. Like many others, the British Government is bound to the doctrine that nuclear weapons have a part to play in military defence. To suppose from the outset that the survival of even individuals is improbable or irrelevant is to give a potential adversary a powerful advantage, the knowledge that its opponents will be fearful for their survival. That is the gap the Home Office seeks to fill. Its attempts so far to do so are the best that could have been accomplished, but are also unconvincing. It would be more beneficially persuasive of British (and other) public opinion if the present British Government were to revert to its immediate predecessor's stance and publicly acknowledge that nuclear war means death (the manner of which cannot be foretold). One consequence would be that the public interest in the progress of arms control negotiations would be enhanced. Another would be that the diversionary attention given to sober reports (like that of the British Medical Association) but also to scary documents intended to frighten would be diminished.

\section{The worm in the bud Koestler, a courageous libertarian, should not have exercised his last freedom - suicide.}

Mr ARTHUR KOESTLER, who died last week in London in a suicide pact with his wife, was one of the small army of Central European Jews who have since the Second World War enlivened the English-speaking world and made it think. The value of his contribution to literature is beyond dispute. His novel Darkness at Noon (1940), born of his revulsion from the corruption of the Soviet state by Stalinism, is, however, more than merely 